\title{
Rab27a mediates the tight docking of insulin granules onto the plasma membrane during glucose stimulation
}

\author{
Kazuo Kasai, ${ }^{1}$ Mica Ohara-Imaizumi, ${ }^{2}$ Noriko Takahashi, ${ }^{3,4}$ Shin Mizutani, ${ }^{1}$ Shengli Zhao, ${ }^{1}$ \\ Toshiteru Kikuta, ${ }^{2}$ Haruo Kasai, ${ }^{3}$ Shinya Nagamatsu, ${ }^{2}$ Hiroshi Gomi, ${ }^{1}$ and Tetsuro Izumi ${ }^{1}$
}

${ }^{1}$ Department of Molecular Medicine, Institute for Molecular and Cellular Regulation, Gunma University, Maebashi, Japan. ${ }^{2}$ Department of Biochemistry, Kyorin University School of Medicine, Mitaka, Japan. ${ }^{3}$ Department of Cell Physiology, National Institute for Physiological Sciences and the Graduate University of Advances Studies, Okazaki, Japan. ${ }^{4}$ Precursory Research for Embryonic Science and Technology, Japan Science and Technology Agency, Kawaguchi, Japan.

\begin{abstract}
The monomeric small GTPase Rab27a is specifically localized on both secretory granules and lysosome-related organelles. Although natural mutations of the Rab27a gene in human Griscelli syndrome and in ashen mice cause partial albinism and immunodeficiency reflecting the dysfunction of lysosome-related organelles, phenotypes resulting from the defective exocytosis of secretory granules have not been reported. To explore the roles of Rab27a in secretory granules, we analyzed insulin secretion profiles in ashen mice. Ashen mice showed glucose intolerance after a glucose load without signs of insulin resistance in peripheral tissues or insulin deficiency in the pancreas. Insulin secretion from isolated islets was decreased specifically in response to high glucose concentrations but not other nonphysiological secretagogues such as high $\mathrm{K}^{+}$concentrations, forskolin, or phorbol ester. Neither the intracellular $\mathrm{Ca}^{2+}$ concentration nor the dynamics of fusion pore opening after glucose stimulation were altered. There were, however, marked reductions in the exocytosis from insulin granules predocked on the plasma membrane and in the replenishment of docked granules during glucose stimulation. These results provide the first genetic evidence to our knowledge for the role of Rab27a in the exocytosis of secretory granules and suggest that the Rab27a/effector system mediates glucose-specific signals for the exocytosis of insulin granules in pancreatic $\beta$ cells.
\end{abstract}

\section{Introduction}

Membrane traffic is fundamental to the integrity of eukaryotic cells and is regulated by conserved protein families, such as soluble $\mathrm{N}$-ethylmaleimide-sensitive factor attachment protein receptors (SNAREs) and Rab GTPases. Compared with the established roles of SNARE proteins, which mediate membrane fusion through the formation of a 4-helix bundle in a protein complex, the functions of Rab proteins often remain elusive. This may be because Rab proteins appear to play modulatory roles rather than mechanical ones and because they execute versatile functions by binding to various types of effector proteins. Furthermore, the potentially redundant functions of numerous Rab proteins differentiated in higher eukaryotes might obscure the phenotypes of individual mutants in genetic studies.

Among Rabs, the Rab27 subfamily, which consists of Rab27a and Rab27b, is known to function in regulated secretory pathways $(1,2)$. Each of these pathways harbors a specific organelle that stores bioactive substances and releases them in response to extracellular stimuli. Two major types of organelles can be distinguished by their morphological appearance, release kinetics, and biogenesis: synaptic vesicles in neurons and secretory granules in endocrine and exocrine cells (3). Recently, a third class of organelles, those that are released in a regulated fashion, has been identified; these are called lysosomerelated organelles or secretory lysosomes (4). These organelles, which

Nonstandard abbreviations used: $\left[\mathrm{Ca}^{2+}\right]_{\mathrm{i}}$, intracellular $\mathrm{Ca}^{2+}$ concentration; $\mathrm{K}_{\mathrm{ATP}}$ channel, ATP-sensitive $\mathrm{K}^{+}$channel; PMA, phorbol-12-myristate-13-acetate; SNARE, soluble $N$-ethylmaleimide-sensitive factor attachment protein receptor; TIRFM, total internal reflection fluorescence microscopy.

Conflict of interest: The authors have declared that no conflict of interest exists.

Citation for this article: J. Clin. Invest. 115:388-396 (2005)

doi:10.1172/JCI200522955. include melanosomes in melanocytes and lytic granules in cytotoxic T-lymphocytes, have unique biogenesis related to lysosomes and distinct modes of exocytosis. Rab27a and/or Rab27b are commonly located on these secretory organelles and regulate the exocytosis using multiple effector proteins $(5,6)$. Importantly, mutations of the Rab27a gene discovered in human Griscelli syndrome (7) and in the mouse coatcolor mutant ashen (8) cause partial albinism and immunodeficiency, reflecting the dysfunction of lysosome-related organelles. By contrast, phenotypes that result from defects in the exocytosis of secretory granules have not been reported either in these human subjects or in mice, although Rab27a is clearly demonstrated to be localized on secretory granules and to affect hormone secretion in endocrine cells (9).

In the present study, we examined the exocytosis of insulin granules of Rab27a-mutated ashen mice, because the functional roles of Rab27a and its effector granuphilin have been most extensively studied among secretory granules (9-12). By using various morphological, physiological, and biochemical techniques, we found that insulin secretion is impaired specifically in response to a physiological secretagogue, glucose, but not to other, nonphysiological secretagogues. The exocytosis from insulin granules predocked on the plasma membrane and the refilling of docked granules during glucose stimulation were markedly affected in pancreatic $\beta$ cells of ashen mice. This study is the first to our knowledge to provide in vivo genetic evidence for the role of Rab27a in the exocytotic pathway of secretory granules.

\section{Results}

Expression of Rab27a, Rab27b, and granuphilin in pancreas. We first examined the expression of Rab27a and its related molecules in pancreatic islets (Figure 1A). As described previously (9), Rab27a 
A
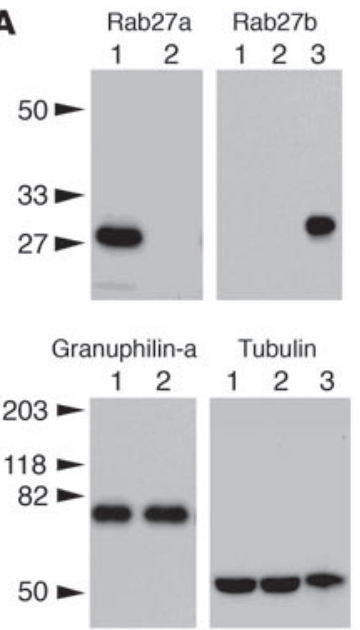

B
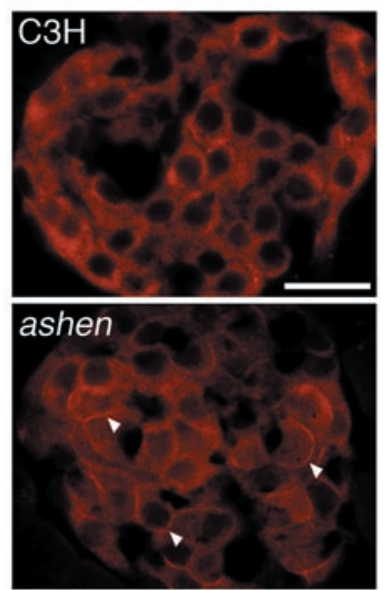

Figure 1

Expression of Rab27a, Rab27b, and granuphilin in pancreatic islets. (A) An equal amount of protein $(20 \mu \mathrm{g})$ from the pancreatic islets of 17-week-old male $\mathrm{C} 3 \mathrm{H} / \mathrm{He}$ (lane 1) and ashen mice (lane 2) was separated by electrophoresis for immunoblotting with anti-Rab27a, anti-Rab27b, or anti-granuphilin ( $\alpha \mathrm{Grp}-\mathrm{aC}$ ) antibodies. The expression levels of $\alpha$-tubulin were also examined for normalization. For the immunoblotting with anti-Rab27b and anti- $\alpha$-tubulin antibodies, $20 \mu \mathrm{g}$ of protein from the pituitary of $\mathrm{C} 3 \mathrm{H} / \mathrm{He}$ mice were loaded on lane 3 for the reference. Numbers to the left of each panel are molecular masses in $\mathrm{kDa}$. (B) The pancreas organs of 17-week-old male $\mathrm{C} 3 \mathrm{H} / \mathrm{He}$ (upper) or ashen mice (lower) were immunostained with anti-granuphilin antibodies ( $\alpha$ Grp-N). Granuphilin is distinguishably concentrated along the plasma membrane in ashen $\beta$ cells (arrowheads) compared with control $\beta$ cells, although the expression levels are similar. Scale bar: $20 \mu \mathrm{m}$.

protein was highly expressed in pancreatic islets of control C3H/He mice. By contrast, it was not detected in the islets of ashen mice, which is consistent with previous reports showing the lack of detectable Rab27a protein in ashen-derived cytotoxic $\mathrm{T}$ lymphocytes $(13,14)$ and platelets $(15)$. Because the Rab27a protein is truncated due to a splice site mutation in ashen mice (8), the mutant protein either is unstable or loses its immunoreactivity. In either case, the mutant Rab27a protein is probably nonfunctional because it lacks some of the GTP-binding pockets. Rab27b, on the other hand, was barely detectable in the islets but was significantly expressed in the pituitary of control mice, as reported previously (16). The expression level of granuphilin, a Rab27a effector in pancreatic $\beta$ cells (9), was not altered in ashen islets, in contrast to another Rab27a effector, melanophilin, which is severely downregulated in ashen melanocytes (17).

\section{Figure 2}

In vivo phenotypes of ashen and $\mathrm{C} 3 \mathrm{H} / \mathrm{He}$ mice. All the phenotypes were derived from male $\mathrm{C} 3 \mathrm{H} / \mathrm{He}$ (white bars or open circles) or ashen (black bars or filled circles) mice. Body weight (A), blood glucose concentrations during an intraperitoneal glucose tolerance test (B), and total insulin content in the pancreas (D) were measured at 15 weeks of age. An intraperitoneal insulin tolerance test (C) was performed at 16 weeks of age, and its results are expressed as a percentage of the initial blood glucose concentration. Values are mean \pm SE $(\mathbf{A}$ and $\mathbf{B}$, $n=8$ for $\mathrm{C} 3 \mathrm{H} / \mathrm{He}, n=7$ for ashen; $\mathbf{C}, n=5$ for $\mathrm{C} 3 \mathrm{H} / \mathrm{He}$ and ashen; $\mathbf{D}$, $n=8$ for $\mathrm{C} 3 \mathrm{H} / \mathrm{He}$ and ashen). The statistical significance of differences between means was assessed by Student's $t$ test. ${ }^{*} P<0.05$, ${ }^{\star \star} P<0.005,{ }^{* \star *} P<0.0005$ vs. $\mathrm{C} 3 \mathrm{H} / \mathrm{He}$ mice.

Immunohistochemical analysis of mouse pancreas specimens confirmed that Rab27a was expressed in insulin-positive $\beta$ cells of control C3H/He mice, as reported previously (9), but not in those of ashen mice (data not shown). By contrast, Rab27b was expressed in exocrine and peripheral islet cells, but not in $\beta$ cells (H. Gomi, $\mathrm{S}$. Zhao, and T. Izumi, unpublished observations). The islet architecture of ashen mice was normal, including a mantle structure between $\beta$ and non- $\beta$ cells, and the expression levels of pancreatic hormones were not significantly reduced in ashen islets (data not shown, but see Figure 1B). While the lack of Rab27a did not affect the expression level of its effector granuphilin (Figure 1A), its intracellular location was significantly affected. The distribution of granuphilin was distinguishably shifted to the plasma membrane in ashen $\beta$ cells compared with its diffuse cytoplasmic distribution in control $\beta$ cells (Figure 1B). Alteration in the subcellular localization in Rab27a-deficient $\beta$ cells strongly supports our previous proposals that granuphilin is associated with secretory granules through Rab27a and that it is an effector of Rab27a, but not of Rab3a, in vivo, despite its affinities to both Rab proteins in vitro (9).

Glucose tolerance and related in vivo phenotypes. Because Rab27b is coexpressed and functionally redundant with Rab27a in platelets (15), the lack of Rab27b in the pancreatic $\beta$ cells of ashen mice makes them an excellent subject of study for the evaluation of Rab27a function. We first examined in vivo phenotypes that might be affected by potential insulin secretion defects in ashen $\beta$ cells. Body weight (Figure 2A) and blood glucose levels examined in mice fed ad libitum (data not shown) or in fasting mice (Figure 2B) did not differ between ashen and $\mathrm{C} 3 \mathrm{H} / \mathrm{He}$ mice. Blood glucose levels after a glucose load, however, were significantly higher in ashen mice (Figure 2B). Although it is generally difficult to measure small changes in plasma insulin levels accurately from a limited amount of samples in mice, unless they have marked hyperinsulinemia (see the examples in ref. 18), plasma insulin levels at fasting or during a glucose tolerance test were not significantly different, except at 120 minutes after the glucose load, at which point the levels were slightly higher in ashen mice (data not shown). Although the hyperglycemia with normoinsulinemia

A
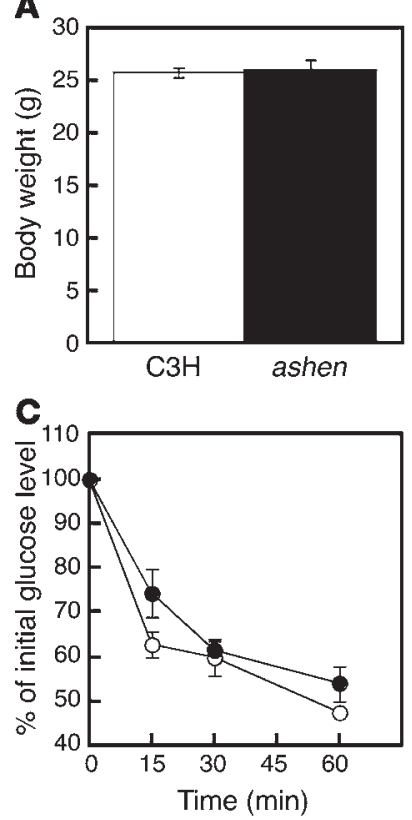
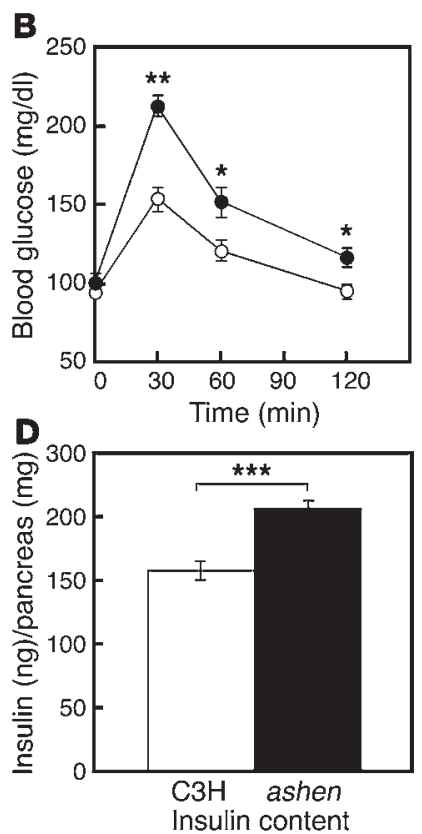

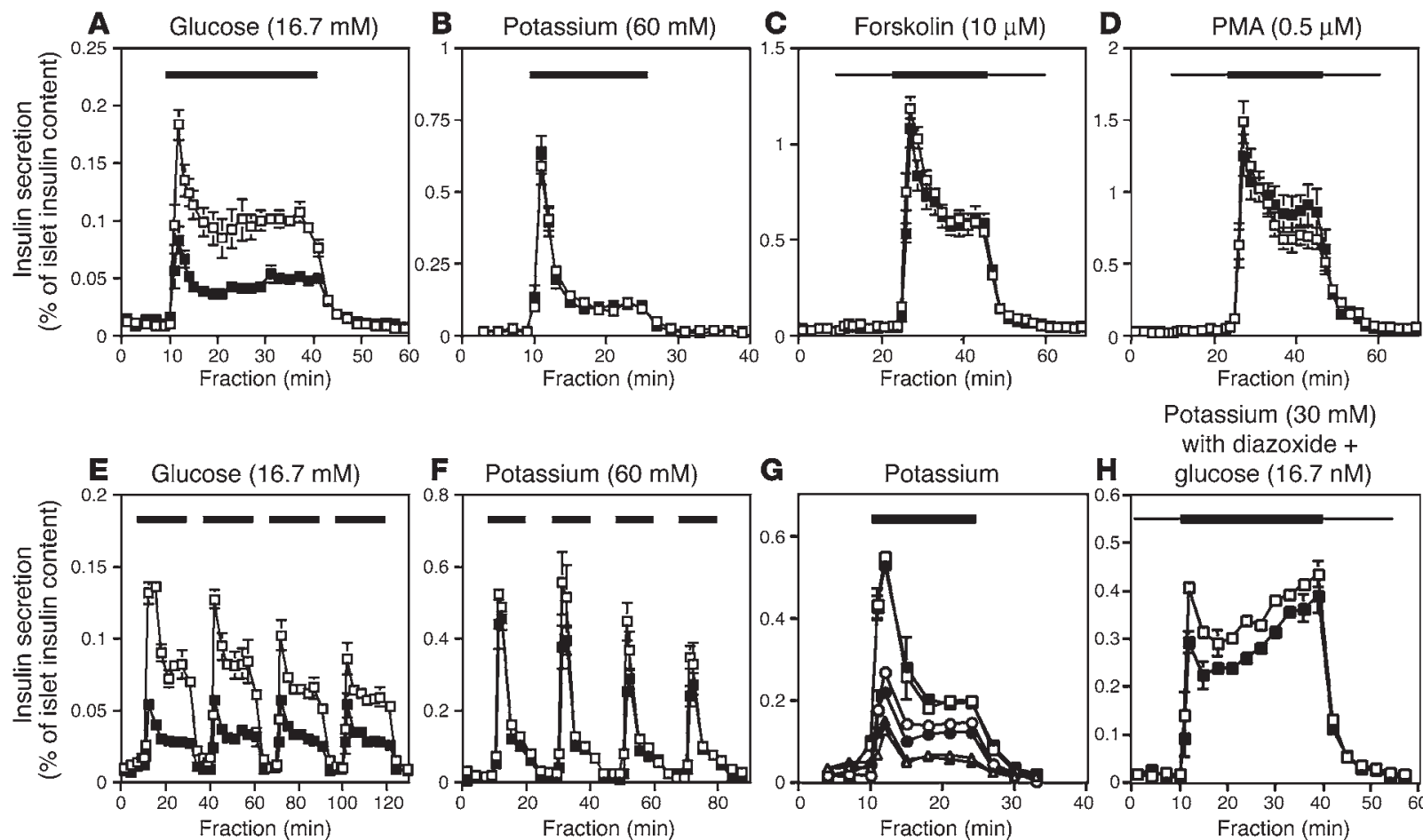

Potassium $(30 \mathrm{mM})$ with diazoxide +

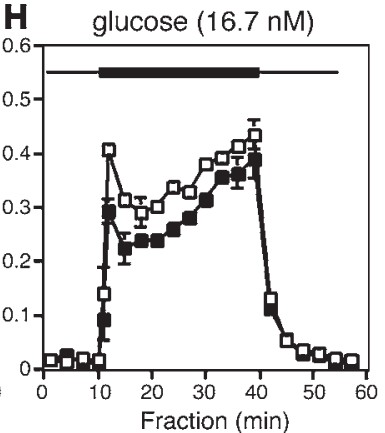

Figure 3

Insulin secretion profiles of perifused islets. Insulin secretion was examined in islets isolated from age-matched (15-17 weeks of age) male C3H/He (open symbols) or ashen mice (filled symbols). The islets were stabilized by perifusion of standard low-glucose (2.8 mM) Krebs-Ringer buffer for 10 minutes, after which an appropriate secretagogue was applied. (A and $\mathbf{B})$ Islets were stimulated by $16.7 \mathrm{mM}$ glucose for 30 minutes $(\mathbf{A} ; n=9$ for each strain) or with $60 \mathrm{mM} \mathrm{KCl}$ for 15 minutes $(\mathbf{B} ; n=6)$. (C and $\mathbf{D})$ Islets were stimulated by $16.7 \mathrm{mM}$ glucose for 30 minutes in the continuous presence of either forskolin $(\mathbf{C}, 10 \mathrm{mM} ; n=8)$ or PMA $(\mathbf{D}, 0.5 \mathrm{mM} ; n=8)$. (E and $\mathbf{F})$ Islets were stimulated 4 times by either $16.7 \mathrm{mM}$ glucose for 20 minutes $(\mathbf{E} ; n=3)$ or by $60 \mathrm{mM} \mathrm{KCl}$ for 10 minutes $(\mathbf{F} ; n=3)$, with 10-minute intervals of the standard buffer. (G) Islets were stimulated by 60 mM (squares), $30 \mathrm{mM}$ (circles), or $20 \mathrm{mM} \mathrm{KCl}$ (triangles) for 15 minutes, followed by the standard buffer for 15 minutes ( $n=3$ for each condition and strain). (H) Islets were perifused with buffer containing $250 \mu \mathrm{M}$ diazoxide and $16.7 \mathrm{mM}$ glucose for 10 minutes. They were further perifused with the buffer containing $30 \mathrm{mM} \mathrm{KCl}$ for 30 minutes, in the continuous presence of diazoxide and glucose ( $n=3$ for each strain). Values are mean $\pm \mathrm{SE}$.

or slight hyperinsulinemia upon glucose challenge might suggest the presence of insulin resistance, insulin tolerance tests $(0.75 \mathrm{U}$ human insulin/ $\mathrm{kg}$ body weight) revealed comparable insulin sensitivity between ashen and control mice (Figure 2C). The tests with smaller doses of insulin (0.1-0.5 U/kg) after overnight fasting also showed similar insulin sensitivity (data not shown). Insulin content in total pancreas was increased by 1.3 -fold in ashen mice compared with controls (Figure 2D), which may reflect an impairment of insulin secretion. These findings indicate that ashen mice have glucose intolerance without signs of insulin resistance in peripheral tissues or absolute insulin deficiency in pancreatic $\beta$ cells.

Insulin secretion profiles in perifused islets. Because the overexpression of active forms of Rab27a has been shown to augment insulin secretion in the cultured $\beta$-cell line MIN6 (9), the lack of functional Rab27a may induce insulin secretion defects in ashen mice. We incubated pancreatic islets, isolated from $\mathrm{C} 3 \mathrm{H} / \mathrm{He}$ or ashen mice, overnight in culture medium to decrease potential environmental effects, such as differences in blood glucose levels, in vivo. They were then examined for the ability to secrete insulin in response to several secretagogues by perifusion analyses. Insulin secretion in response to a high glucose level $(16.7 \mathrm{mM})$ was significantly reduced in both the first (approximately 5 minutes) and second phases in ashen islets (repeated measure ANOVA, $P<0.0001)$, and the accumulated glucose-induced insulin secretion over 30 minutes was diminished by approximately $50 \%$ compared with the control islets (Figure 3A). Surprisingly, the reduction in insulin release was specific to glucose stimulation. Insulin secretion in response to depolarization induced by high $\mathrm{K}^{+}$ concentration $(60 \mathrm{mM})$ was normal in ashen islets (Figure $3 \mathrm{~B}$ ). Furthermore, both forskolin (activator of adenylate cyclase) and phorbol-12-myristate-13-acetate (PMA; protein kinase C activator) stimulated insulin secretion in the presence of high glucose levels indistinguishably between ashen and control islets (Figure 3, $\mathrm{C}$ and $\mathrm{D})$. These findings indicate that the defect in insulin secretion in ashen islets does not simply reflect a general decrease in the releasable pool of granules. Consistent with this idea, insulin secretion was normal even after repeated exposure to high concentrations of $\mathrm{K}^{+}$in ashen islets (Figure $3 \mathrm{~F}$ ). By contrast, insulin secretion was decreased at each of the repeated exposures to the glucose stimuli (Figure 3E; $P<0.0001$ ), suggesting that Rab27a is specifically required for the replenishment of a pool of granules released by glucose.

The stimulation with high $\mathrm{K}^{+}$, forskolin, or PMA induced much higher insulin secretion compared with the $16.7 \mathrm{mM}$ glucose stimulation (note differences in the ordinates of each panel in Figure 3). Stronger stimuli might have obscured subtle functional differences between the 2 kinds of islets. The lower concentrations of $\mathrm{KCl}(20 \mathrm{mM}$ or $30 \mathrm{mM})$ induced an insulin secretion at the 


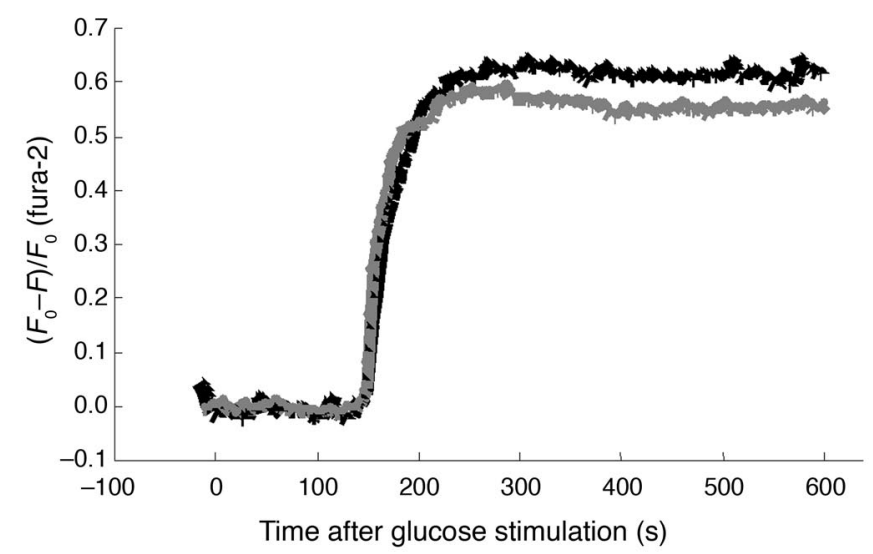

Figure 4

The rise in cytosolic $\mathrm{Ca}^{2+}$ concentration in response to glucose stimulation. The cytosolic $\mathrm{Ca}^{2+}$ concentration was measured using Fura-2 acetoxymethyl ester by two-photon excitation imaging in pancreatic $\beta$ cells of either $\mathrm{C} 3 \mathrm{H} / \mathrm{He}$ (gray) or ashen (black) mice and was represented by $\left(F_{0}-F\right) / F_{0}$, where $F_{0}$ and $F$ stand for resting and fluorescence and fluorescence after $20 \mathrm{mM}$ glucose stimulation, respectively. Mean values are shown $(n=4)$.

peak that was equivalent to that induced by $16.7 \mathrm{mM}$ glucose during perifusion of the control islets (Figure 3, A and G). The same treatment in ashen islets evoked an indistinguishable amount and manner of insulin secretion (Figure $3 \mathrm{G}$ ). Therefore, ashen $\beta$ cells showed specific defects in insulin secretion in response to glucose, but not to high $\mathrm{K}^{+}$, independent of the strength of the depolarization stimuli. These findings indicate qualitative differences in the mode of exocytosis induced by glucose and that induced by other, nonphysiological secretagogues.

Although high $\mathrm{K}^{+}$stimulation physically induces membrane depolarization and a subsequent rise of intracellular $\mathrm{Ca}^{2+}$ concentration $\left(\left[\mathrm{Ca}^{2+}\right]_{\mathrm{i}}\right)$, glucose stimulates intracellular metabolism and ATP production, which is thought to induce additional effects as well as triggering depolarization by the closure of ATP-sensitive $\mathrm{K}^{+}\left(\mathrm{K}_{\text {ATP }}\right)$ channel. This amplifying effect by glucose has classically been evaluated by the amount of insulin secreted in the presence of diazoxide, an opener of $\mathrm{K}_{\mathrm{ATP}}$ channels $(19,20)$. As expected, $250 \mu \mathrm{M}$ diazoxide inhibited insulin secretion induced by $16.7 \mathrm{mM}$ glucose in both ashen and control islets (see the insulin secretion during the first 10 minutes in Figure $3 \mathrm{H}$ ). To induce insulin secretion, the islets were depolarized by $30 \mathrm{mM} \mathrm{KCl}$ in the continuous presence of diazoxide and $16.7 \mathrm{mM}$ glucose. The amount of insulin secreted was not significantly different, though slightly reduced, in the ashen islets compared with the control islets (Figure $3 \mathrm{H}$ ). These findings suggest that the amplifying pathway by glucose is largely intact in ashen $\beta$ cells.

Analysis of the exocytosis of insulin granules by two-photon excitation imaging. To explore the mechanism responsible for the decrease in glucose-induced insulin secretion, we directly examined the exocytosis of granules by 2-photon excitation imaging (21). This newly innovated morphological technique enables us to precisely monitor individual exocytotic events per the constant area, as well as other parameters relevant to exocytosis, in isolated islets. Both the amplitude and time course of the glucose-induced rise in $\mathrm{Ca}^{2+}$ concentration measured using Fura-2 was not different between ashen and $\mathrm{C} 3 \mathrm{H} / \mathrm{He}$ mice (Figure 4 and Table 1), which suggests normal glucose metabolism and ATP production in ashen $\beta$ cells. Fusion pore dynamics examined by measuring latency for the onset of staining with fluorescent markers of different sizes was also unchanged in ashen islets (Table 1). However, the exocytotic events during the first and second 5 minutes were significantly reduced (Table 1 ), which is consistent with the findings of the perifusion assays (Figure 3A). These results independently demonstrated the reduction of glucose-induced fusion events and excluded the possibility of changes in the dynamics of $\left[\mathrm{Ca}^{2+}\right]_{i}$ or fusion pore opening in ashen islets.

Analysis of the exocytosis of insulin granules by total internal reflection fluorescence microscopy. We next utilized total internal reflection fluorescence microscopy (TIRFM) to investigate the exocytotic events occurring just beneath the plasma membrane in isolated pancreatic $\beta$ cells. TIRFM detects cytoplasmic events within $100 \mathrm{~nm}$ of the plasma membrane (22). We first immunostained endogenous insulin in fixed pancreatic $\beta$ cells. Because fluorescent imaging by TIRFM can depict the single insulin granules closely associated with the plasma membrane (23), we counted the number of morphologically docked granules (Figure 5A). The ashen $\beta$ cells showed a marked decline in the number $\left(130 \pm 34\right.$ per $200 \mu \mathrm{m}^{2}$ in ashen $\beta$ cells vs. $219 \pm 34$ per $200 \mu \mathrm{m}^{2}$ in C $3 \mathrm{H} / \mathrm{He} \beta$ cells; $n=24$ for ashen and $n=21$ for $\mathrm{C} 3 \mathrm{H} / \mathrm{He})$ to $59 \%$ of normal levels $(P<0.0001)$. These findings suggest that granules docked onto the plasma membrane are reduced in ashen $\beta$ cells.

We then observed fusion events of fluorescence-labeled granules by TIRFM in live $\beta$ cells that had been infected with an adenovirus encoding GFP-tagged insulin (23). The fusion events in response to $30 \mathrm{mM} \mathrm{KCl}$ occurred predominantly during the first 5 minutes after the stimulation and were not significantly different between ashen and control $\beta$ cells $(40.1 \pm 5.9$ in $0-5$ minutes in ashen $\beta$ cells vs. $56.7 \pm 6.9$ in $0-5$ minutes for $\mathrm{C} 3 \mathrm{H} / \mathrm{H} 3$ $\beta$ cells, $n=4$ each). There were no significant differences in the exocytosis of previously docked granules $(4.5 \pm 2.1$ in ashen $\beta$ cells vs. $7.5 \pm 2.0$ in $\mathrm{C} 3 \mathrm{H} / \mathrm{He} \beta$ cells) or in that of newly recruited granules $(34.4 \pm 4.4$ in ashen $\beta$ cells vs. $47.7 \pm 6.9$ in $\mathrm{C} 3 \mathrm{H} / \mathrm{He} \beta$ cells). The

\section{Table 1}

Analysis of the exocytosis of insulin granules by 2-photon excitation imaging

\section{$\mathrm{C3H}$}

ashen

Increase in the cytosolic $\mathrm{Ca}^{2+}$ concentration in response to $12 \mathrm{mM}$ glucose

$\left(F_{0}-F\right) / F_{0}$ $0.60 \pm 0.03$

$(n=10)$ $0.63 \pm 0.02^{A}$ $(n=15)$

Exocytotic events within an arbitrary area $\left(2,000 \mu \mathrm{m}^{2}\right)$ in response to $20 \mathrm{mM}$ glucose

First phase (0-300 seconds)

Second phase (300-600 seconds)

$$
\begin{aligned}
& 48.3 \pm 8.0 \quad 28.8 \pm 7.3^{B} \\
& 48.6 \pm 10.8 \quad 39.8 \pm 6.1^{\mathrm{C}} \\
& (n=5) \quad(n=5)
\end{aligned}
$$

Latency (s) for the onset of staining with sulforhodamine B (about $1.4 \mathrm{~nm}$ ) relative to that of staining with 10-kDa dextran (about $6 \mathrm{~nm}$ )

$$
\begin{array}{cc}
1.6 \pm 0.18 & 2.0 \pm 0.21^{A} \\
(n=25) & (n=31)
\end{array}
$$

The statistical significance of differences between means was assesed by Student's $t$ test. ${ }^{A} N S(P>0.05)$. ${ }^{\mathrm{B}} P<0.005 .{ }^{\mathrm{C}} P<0.025$. 
A

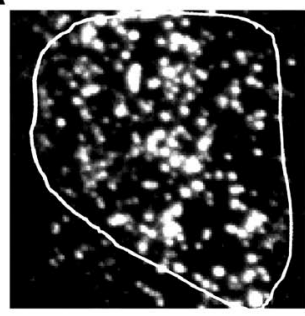

$\mathrm{C} 3 \mathrm{H}$

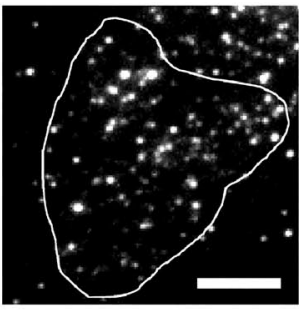

ashen

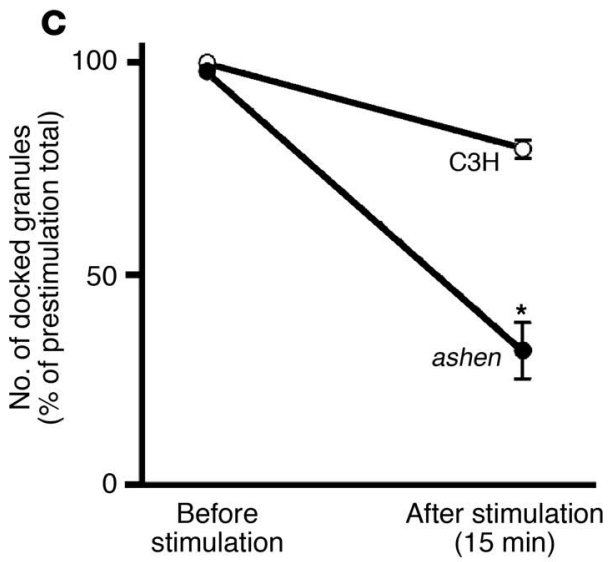

\section{B}
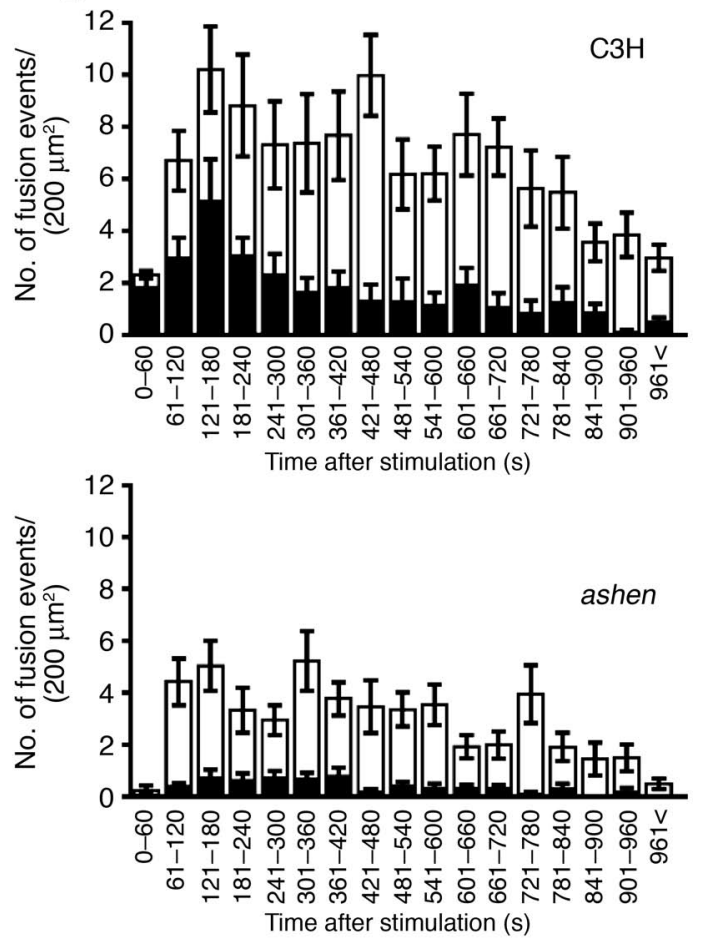

Figure 5

TIRFM analysis of the exocytosis of insulin granules. (A) Pancreatic $\beta$ cells from either $\mathrm{C} 3 \mathrm{H} / \mathrm{He}$ (left) or ashen (right) mice were fixed, immunostained with anti-insulin antibodies, and observed by TIRFM. The surrounding lines represent the outline of cells that are attached to the cover glass. Scale bar: $5 \mu \mathrm{m}$. (B) Pancreatic $\beta$ cells of either $\mathrm{C} 3 \mathrm{H} / \mathrm{He}$ (upper) or ashen (lower) mice were infected with adenoviruses encoding insulin-GFP. Evanescent images in live cells were acquired every 300 milliseconds after glucose stimulation. The fusion events per $200 \mu m^{2}$ were manually counted. The histograms show the number of fusion events at 60 -second intervals after high-glucose (16.7 mM) stimulation. The black bars show the fusion from previously docked granules, whereas the white bars represent that from newly recruited granules. Values are mean \pm SE ( $n=24$ for ashen and $n=21$ for $\mathrm{C} 3 \mathrm{H} / \mathrm{He}$ mice). The statistical significance of differences between means were assessed by repeated-measures ANOVA. (C) The number of morphologically docked granules was counted on the TIRFM images of pancreatic $\beta$ cells that had been infected with adenoviruses encoding insulin-GFP. The number after a glucose stimulation (16.7 mM, 15 minutes) was normalized to that prior to the stimulation in the identical area $\left(200 \mu \mathrm{m}^{2}\right)$ of $\mathrm{C} 3 \mathrm{H} / \mathrm{He}$ (open circles) or ashen (filled circles) $\beta$ cells. Values are mean $\pm \mathrm{SE}(n=4)$. The statistical significance of differences between means was assessed by Student's $t$ test. ${ }^{*} P<0.0005 \mathrm{vs}$. $\mathrm{C} 3 \mathrm{H} / \mathrm{He} \mathrm{mice}$.

fusion events in response to $16.7 \mathrm{mM}$ glucose, however, were significantly decreased (Figure 5B; $15.4 \pm 2.5$ in $0-5$ minutes in ashen $\beta$ cells vs. $34.5 \pm 5.6$ in $0-5$ minutes in $\mathrm{C} 3 \mathrm{H} / \mathrm{He} \beta$ cells, $P<0.05$; and $32.5 \pm 4.2$ in $5-16$ minutes vs. $72.4 \pm 11.5$ in $5-16$ minutes, $P<0.0001 ; n=24$ for ashen and $n=21$ for $\mathrm{C} 3 \mathrm{H} / \mathrm{He}$ ). Remarkably, few fusion events occurred from previously docked granules in ashen $\beta$ cells $(5.8 \pm 1.3$ in $0-16$ minutes in ashen $\beta$ cells vs. $26.3 \pm 4.3$ in $0-16$ minutes in $\mathrm{C} 3 \mathrm{H} / \mathrm{He} \beta$ cells). The exocytosis of newly recruited granules was relatively modestly affected, although it was also significantly reduced $(42.1 \pm 4.2$ in $0-16$ minutes in ashen $\beta$ cells vs. $80.6 \pm 11.2$ in $0-16$ minutes in $\mathrm{C} 3 \mathrm{H} / \mathrm{He} \beta$ cells). We then analyzed the changes in the total number of docked granules during glucose stimulation using the TIRFM images. Comparison of the numbers of docked granules in the identical area before and after glucose stimulation should eliminate the effect of potential differences in infection efficiency between cells. The number of docked granules after 15 minutes of glucose stimulation remained $80.3 \% \pm 2.1 \%$ of the initial number in the control $\beta$ cells (Figure 5C). By contrast, it was markedly decreased to $32.1 \% \pm 6.6 \%$ in ashen $\beta$ cells, indicating that refilling of the pool of docked granules is defective.
Analysis of insulin granules by EM. We next performed the EM examination of pancreatic $\beta$ cells from fixative-perfused mice. It did not reveal any obvious alterations in the number, distribution, or appearance (dense-core formation) of granules in ashen $\beta$ cells (data not shown, but see Figure 6A), except that the average diameter was slightly decreased $(298 \pm 7 \mathrm{~nm}$ in ashen $\beta$ cells vs. $322 \pm 7 \mathrm{~nm}$ in $\mathrm{C} 3 \mathrm{H} / \mathrm{He} \beta$ cells, $P<0.05 ; n=24$ for ashen and $n=25$ for $\mathrm{C} 3 \mathrm{H} / \mathrm{He}$; note that the values represent the mean of the profile diameter in sections but not that of the maximum diameter). To determine whether any of the changes in glucose-stimulated exocytosis identified here are correlated with the finding of EM, islets were first isolated from mice and incubated with either $2.8 \mathrm{mM}$ or $25 \mathrm{mM}$ glucose, and then chemically fixed and subjected to morphometric analysis (Figure 6A). Granules were divided according to the distance from their center to the plasma membrane, and the density of granules in concentric shells below the plasma membrane was calculated relative to the average density of all cytoplasmic granules. Although the density of granules whose centers were located $300-500 \mathrm{~nm}$ from the plasma membrane was not significantly different from the average, the density of granules whose centers were located within $100 \mathrm{~nm}$ of the plasma membrane was much lower 
A

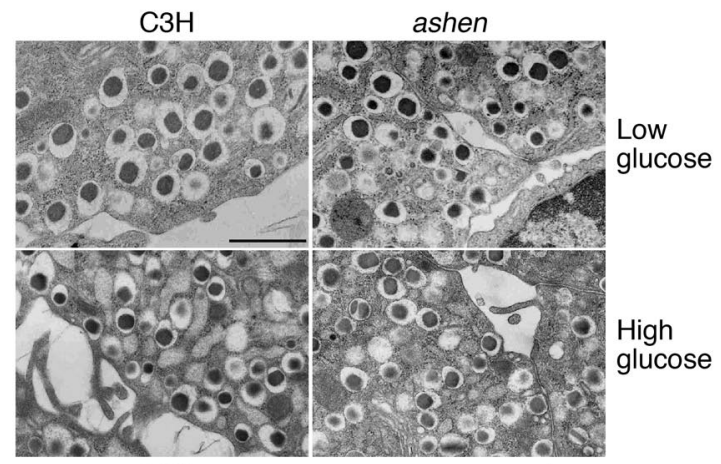

B

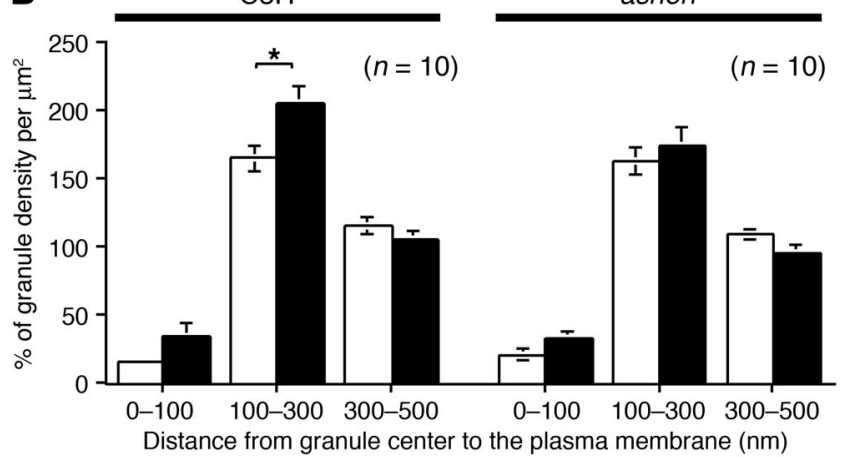

in both nonstimulated and stimulated control $\beta$ cells (Figure 6B, left). Given that the diameter of insulin granules is $300-350 \mathrm{~nm}$, which is equivalent to the previously reported value (24), the latter finding is not surprising because the center of granules should not approach the plasma membrane within their radius. By contrast, the density of granules whose centers reside at $100-300 \mathrm{~nm}$ significantly increased above the average, which may indicate the accumulation of granules docked onto the plasma membrane. This fraction is thought to correspond to the granules visualized by TIRFM considering the TIRFM coverage area (within $100 \mathrm{~nm}$ from the plasma membrane) and the mean diameter of granules $(300-350 \mathrm{~nm})$. Interestingly, the density of this fraction was significantly augmented by the exposure to $25 \mathrm{mM}$ glucose in the control $\beta$ cells. By contrast, the glucose-dependent accumulation of granules beneath the plasma membrane was lacking in ashen $\beta$ cells, although the densities of other fractions were not significantly different from those in the control $\beta$ cells (Figure 6B, right). These findings suggest that glucose has the ability to replenish a pool of docked granules and that this glucose-driven refilling process is impaired in ashen $\beta$ cells.

Complex formation between granuphilin and syntaxin 1a. We previously demonstrated that the Rab27a effector granuphilin directly interacts with syntaxin 1a, a SNARE protein on the plasma membrane (11), and that wild-type granuphilin, but not its mutants that are defective in binding to either Rab27a or syntaxin 1a, promotes the plasma membrane targeting of insulin granules (12). These findings suggest that granuphilin tethers insulin granules and the plasma membrane through interactions with Rab27a and syntaxin 1a, respectively. To examine the complex formation between granuphilin and syntaxin 1a, coimmunoprecipitation experiments were performed with lysates of isolated islets. Although the expression levels of syntaxin 1a and granuphilin were similar between ashen and control islets, the amount of syntaxin 1a coprecipitated

\section{Figure 6}

Ultrastructure of the pancreatic $\beta$ cells. (A) Electron micrographs of $\beta$ cells were taken in nonstimulated (upper) or glucose-stimulated (lower) islets of $\mathrm{C} 3 \mathrm{H} / \mathrm{He}$ (left) and ashen (right) mice. Scale bar: $1 \mu \mathrm{m}$. (B) Relative density of granules below the plasma membrane in nonstimulated (white bars) or glucose-stimulated (black bars) $\beta$ cells of $\mathrm{C} 3 \mathrm{H} / \mathrm{He}$ (left) and ashen (right) mice is shown as a function of the distance from granule center to the plasma membrane $(\mathrm{nm})$. Data are represented as a percentage of the granule density in each concentric shell below the plasma membrane relative to the average density in cytoplasm $(100 \%=$ number of total granules per the area of cytoplasm, that is, the cell area minus the nuclear area). Values are mean \pm SE $(n=10)$. The statistical significance of differences between means was assessed by Student's $t$ test. ${ }^{*} P<0.05$.

with anti-granuphilin antibodies was significantly decreased in ashen islets (Figure 7A, lower panel). The reduction was specific, because the amount of another complex containing syntaxin 1a with Munc18-1 (25) was comparable between ashen and control islets (Figure 7A, upper panel). This finding is compatible with our previous finding that active Rab27a promotes complex formation between granuphilin and syntaxin 1a (11) and may explain the decreased docking of insulin granules with the plasma membrane in ashen $\beta$ cells. Quantification in independent experiments revealed that the amount of granuphilin/syntaxin 1a complex was reduced to approximately $60 \%$ compared with the control (Figure 7B); this value is roughly equivalent to the degree of decrease in the number of docked granules (Figure 5A). The decreased complex formation between syntaxin $1 \mathrm{a}$ and granuphilin also indicated that the redistribution of granuphilin to the peripheral plasma membrane region in ashen $\beta$ cells (Figure 1B) is not due to the increased association with syntaxin $1 \mathrm{a}$.

$\mathbf{A}$

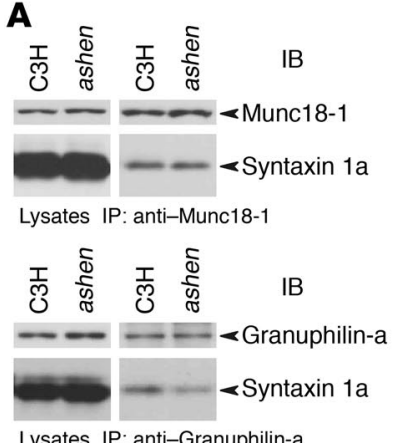

B

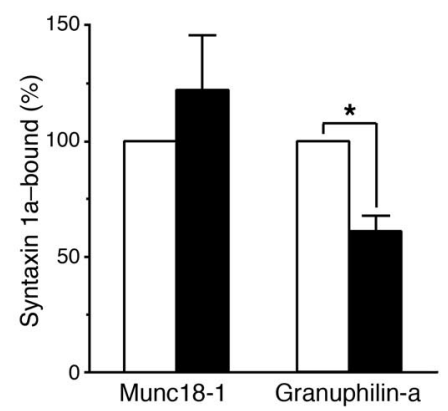

\section{Figure 7}

Protein interactions of syntaxin 1a in pancreatic islets. (A) Protein interactions of syntaxin 1a with either Munc18-1 (upper) or granuphilina (lower) were analyzed in extracts of $\mathrm{C} 3 \mathrm{H} / \mathrm{He}$ or ashen islets. The amount of Munc18-1, granuphilin-a, and syntaxin 1a in each lysate $(5 \mu \mathrm{g}$, left) and $30-40 \%$ of the immunoprecipitates of Munc18-1 or granuphilin-a (right) were examined by immunoblotting with the antibodies indicated. (B) Results of coimmunoprecipitation experiments independently performed as described in $\mathbf{A}$ were gathered for statistics. Relative intensities of syntaxin 1a signals in ashen mice (black bars) to those in $\mathrm{C} 3 \mathrm{H} / \mathrm{He}$ mice (white bars) were calculated and expressed as mean \pm SE from 7 (vs. Munc18-1) and 6 (vs. granuphilin-a) immunoblot preparations. When analyzed by a Wilcoxon signed-ranks test, ashen islets showed significantly reduced interaction of syntaxin 1a with granuphilin-a ( ${ }^{\star} P=0.027$ ), but not with Munc18-1. 


\section{Discussion}

We demonstrate here that insulin secretion in response to a physiological stimulus, glucose, is significantly reduced in ashen $\beta$ cells by 3 independent analyses, which included perifusion, 2-photon excitation imaging, and TIRFM techniques. The possibility of absolute insulin deficiency is excluded because the insulin content in the ashen pancreas is slightly elevated. Neither the rise of $\left[\mathrm{Ca}^{2+}\right]_{\mathrm{i}}$ nor the dynamics of fusion pore opening after a glucose load is altered. These findings indicate that the defect lies in the glucose-stimulated secretory pathway somewhere after the increase in $\left[\mathrm{Ca}^{2+}\right]_{i}$ and before the formation of a fusion pore. TIRFM analysis consistently documented reductions in the numbers of docked granules onto the plasma membrane and in the exocytosis from predocked granules. It also showed that docked granules are not efficiently refilled during glucose stimulation in ashen $\beta$ cells. Furthermore, EM analysis revealed the glucosedependent accumulation of granules beneath the plasma membrane in control $\beta$ cells, but not in ashen $\beta$ cells. These findings indicate a defect in the replenishment of docked granules during glucose stimulation in ashen $\beta$ cells.

The relatively modest findings by EM compared with those by TIRFM about the differences in the number and refilling of docked granules likely result from technical differences inherent between the 2 methods. TIRFM directly observes the plasma membrane, a fusion site, as a 2-dimensional area of a monolayer cell, although the contact zone with the glass coverslip might be artificially affected by reorganization of the cytoskeleton. On the other hand, EM detects the plasma membrane as a contour of a cell embedded in tissue. Because less than $5 \%$ of granules in the section should be released during glucose stimulation when the amount of insulin secreted is estimated relative to the content in cells, it might be difficult to capture resultant morphological changes by EM. Moreover, docked granules themselves may be difficult to identify because there is no specialized docking site like the active zone for synaptic vesicles. It was previously reported that a population of docked granules can be identified by EM only in unfixed, quickly frozen cells (26). Even by using such cryopreservation methods, however, there are discrepant findings concerning the accumulation and preferential exocytosis of morphologically docked granules in chromaffin cells $(26,27)$. Despite these technical differences and difficulties, our TIRFM and EM findings indicate that the dysfunction of Rab27a affects glucose-driven refilling of docked granules and thus reduces glucose-induced exocytosis in both early and late phases. This notion is further corroborated by the perifusion data that insulin secretion is significantly decreased at each of the repeated exposures to the glucose stimuli in ashen $\beta$ cells.

In contrast to glucose stimulation, ashen $\beta$ cells do not reveal any decrease of insulin secretion in response to high $\mathrm{K}^{+}$, whether it is given once or repeatedly, or in response to other pharmacological enhancers. Although disturbance of vesicle transport by alteration of Rab protein is not surprising, the secretagogue-specific defect in exocytosis identified here was unexpected. What mechanism is underlying this phenomenon? It is unlikely that glucose metabolism itself is impaired by the Rab27a mutation. Indeed the amplitude and time course of $\left[\mathrm{Ca}^{2+}\right]_{i}$ increase in response to glucose, which is dependent on ATP generation through glucose metabolism, is indistinguishable between ashen and control $\beta$ cells. Furthermore, high $\mathrm{K}^{+}-$and glucose-induced insulin secretion measured in the presence of diazoxide, which is thought to reflect a pathway amplified by glucose metabolism $(19,20)$, is largely intact in ashen $\beta$ cells. These findings indicate that the suppression of glucose-stimulated insulin secretion does not involve an effect on glucose metabolism per se. Although both high $\mathrm{K}^{+}$and glucose induce membrane depolarization and subsequent $\mathrm{Ca}^{2+}$ influx through activation of voltage-dependent $\mathrm{Ca}^{2+}$ channels in pancreatic $\beta$ cells, the mechanism for inducing depolarization is different. High $\mathrm{K}^{+}$induces it physically, whereas glucose does so by closing $\mathrm{K}_{\mathrm{ATP}}$ channels through the ATP production. Accordingly, the 2 stimuli elicit distinct patterns and time courses of $\left[\mathrm{Ca}^{2+}\right]_{i}$ change $(20,24)$. High $\mathrm{K}^{+}$elicits a large but transient peak of elevated $\left[\mathrm{Ca}^{2+}\right]$, which returns spontaneously towards the prestimulatory level despite the continuous presence of high $\mathrm{K}^{+}$, whereas glucose induces a biphasic response in $\left[\mathrm{Ca}^{2+}\right]_{\text {, }}$, consisting of an initial large increase and long-lasting oscillations that remain throughout the glucose application. These distinct $\left[\mathrm{Ca}^{2+}\right]_{\mathrm{i}}$ changes might differentially affect the action of Rab27a and its effectors by influencing protein-protein or protein-lipid interactions. Another possibility is that glucose generates signals other than $\left[\mathrm{Ca}^{2+}\right]_{i}$ that act on the Rab27a system. It has recently been reported that glucose-induced reduction of the cytoplasmic ADP concentration activates phosphatidylinositol 4-kinase activity in pancreatic $\beta$ cells and that the resultant increase in phosphoinositides enhances the number of releasable granules (28). The production of phosphoinositides on the plasma membrane might recruit Rab27a effectors because many of them contain C2 domains that have potential affinity to these lipids $(1,6)$.

The function of Rab27a in the docking process of insulin granules is consistent with the known property of granuphilin, a principal Rab27a effector in pancreatic $\beta$ cells. It has been shown that granuphilin directly binds to the plasma membrane-anchored SNARE, syntaxin 1a, and that active Rab27a enhances the complex formation in the $\beta$ cell line MIN6 (11). Furthermore, wild-type granuphilin, but not its mutants that are defective in binding to Rab27a or syntaxin $1 \mathrm{a}$, promotes the plasma membrane targeting of insulin granules (12). Moreover, previous TIRFM analysis has shown that insulin granules are preferentially docked to syntaxin 1a clusters in the intact plasma membrane of MIN6 cells (29). The correlated reductions in the docking of granules and the complex formation in ashen $\beta$ cells, shown here, further support a role of the interaction between granuphilin and syntaxin 1a in the docking process. It is possible, however, that granuphilin also mediates this process by other mechanisms. As described above, its C-terminal C2 domains may contribute to the docking process through an affinity to membrane phospholipid, because granuphilin appears to associate with the plasma membrane even when its interaction with syntaxin $1 \mathrm{a}$ is decreased in ashen $\beta$ cells.

In summary, the present study has provided the first genetic documentation to our knowledge for the role of Rab27a in the exocytosis of secretory granules. It also has given an insight into physiological aspects of insulin secretion. Our findings suggest that glucose promotes the replenishment of a pool of docked granules by using the activity of Rab27a. The defect in the docking of granules in ashen $\beta$ cells is reminiscent of the finding that ashen lytic granules do not reach the plasma membrane at the immunological synapse, although they are polarized to the target cell interface (14). There is, however, a marked difference between the 2 organelles in terms of their efficiencies of exocytosis. Although ashen lytic granules are almost incapable of subsequent fusion $(13,14)$, ashen secretory granules are substantially released. The significance of Rab27a in physiological insulin secretion is supported by the 
in vivo glucose intolerant phenotype of ashen mice. Patients with Griscelli syndrome may also exhibit glucose intolerance, although most of them die in childhood from hemophagocytotic syndrome without bone-marrow transplantation (30).

\section{Methods}

Mice, phenotypic characterization, and tissue preparation. All animal experiments were performed in accordance with the rules and regulations of the Animal Care and Experimentation Committee, Gunma University, Showa Campus. The ash/ash (C3H/He background) and control C3H/He mice were kindly provided by N.A. Jenkins (National Cancer Institute, Frederick, Maryland, USA). All mice were weaned at 4 weeks of age and had free access to water and standard laboratory chow (CE-2; CLEA Japan) in an air-conditioned room with a 12-hour light/12-hour dark cycle. An intraperitoneal glucose tolerance test $(1 \mathrm{~g}$ glucose $/ \mathrm{kg}$ body weight) and an intraperitoneal insulin tolerance test $(0.75 \mathrm{U}$ human insulin $/ \mathrm{kg}$ body weight) were performed as described previously (18). Blood glucose levels were determined by a glucose oxidase method using Glutest sensor and Glutest Pro GT-1660 (Sanwa Kagaku Kenkyujyo). The plasma insulin concentration was measured by a LBIS mouse insulin ELISA kit (U-type; Shibayagi Co.). For the measurement of insulin content, the pancreata were excised and weighed, and each was then cut into small pieces and frozen by liquid nitrogen. Insulin was extracted by homogenization using a glass-Teflon homogenizer (1,300 rpm, 30 strokes) in an acid-ethanol solution $(70 \%$ ethanol and $0.18 \mathrm{M} \mathrm{HCl}$ ) and then by sonication for 20 seconds. After centrifugation at $3,000 \mathrm{~g}$ for 10 minutes, the immunoreactive insulin in the supernatant was measured as described previously (31).

Immunoblotting and immunostaining analyses. Rabbit anti-granuphilin antibodies, $\alpha \mathrm{Grp}-\mathrm{aC}$ that recognizes granuphilin-a (10) and $\alpha \mathrm{Grp}-\mathrm{N}$ that recognizes both granuphilin-a and -b (9), and rabbit anti-Rab27b antibodies against glutathione-S-transferase-fused mouse Rab27b protein (16) were previously described and characterized. Mouse anti-Rab27a and anti$\alpha$-tubulin monoclonal antibodies were purchased from BD Biosciences - Pharmingen and Sigma-Aldrich, respectively. Immunoblotting and immunostaining analyses were performed as described previously (16).

Perifusion assays in isolated islets. Islets were isolated from cervically dislocated mice by pancreatic duct injection of $500 \mathrm{U} / \mathrm{ml}$ of collagenase solution (type XI; Sigma-Aldrich) followed by digestion at $37^{\circ} \mathrm{C}$ for 30 minutes with mild shaking, as described previously (31). Islets were picked up by hand selection under a dissecting microscope and cultured overnight in RPMI 1640 medium (11 mM glucose) supplemented with $7.5 \%$ fetal calf serum, 100 units $/ \mathrm{ml}$ penicillin, and $100 \mu \mathrm{g} / \mathrm{ml}$ streptomycin. Thirty islets were placed at the bottom of a $1-\mathrm{ml}$ syringe that had been cut to a volume of $400 \mu \mathrm{l}$ and plugged with cotton. They were perifused with low-glucose KrebsRinger buffer (15 mM HEPES [pH 7.4], $120 \mathrm{mM} \mathrm{NaCl}, 5 \mathrm{mM} \mathrm{KCl,} 2 \mathrm{mM}$ $\mathrm{CaCl}_{2}, 1 \mathrm{mM} \mathrm{MgCl}_{2}, 24 \mathrm{mM} \mathrm{NaHCO}_{3}, 0.1 \%$ bovine serum albumin, and 2.8 $\mathrm{mM}$ glucose) at a constant flow rate of $1.0 \mathrm{ml} / \mathrm{min}$ for 30 minutes. After this stabilization period, they were further perifused with the same buffer for 10 minutes followed by the buffer containing various secretagogues.

For glucose stimulation, islets were perifused with the high-glucose buffer $(16.7 \mathrm{mM})$ for 30 minutes, followed by that containing $2.8 \mathrm{mM}$ glucose for 20 minutes. For stimulation by high $\mathrm{K}^{+}$concentration, islets were perifused with buffer containing $60 \mathrm{mM} \mathrm{KCl}$ plus $65 \mathrm{mM} \mathrm{NaCl}, 30 \mathrm{mM}$ $\mathrm{KCl}$ plus $95 \mathrm{mM} \mathrm{NaCl}$, or $20 \mathrm{mM} \mathrm{KCl}$ plus $105 \mathrm{mM} \mathrm{NaCl}$ for $15 \mathrm{~min}$ utes, followed by the standard buffer for 15 minutes. For the application of forskolin (Sigma-Aldrich) or PMA (Calbiochem-Novabiochem), islets were perifused in the continuous presence of either drug with the standard buffer for 15 minutes, then with the high-glucose buffer for 20 minutes, with the standard buffer for 15 minutes, and were finally perifused without the drug for 10 minutes. For repeated stimulation, the islets were perifused with the standard buffer and then stimulated 4 times by either the high-glucose buffer for 20 minutes or the buffer containing $60 \mathrm{mM}$ $\mathrm{KCl}$ plus $65 \mathrm{mM} \mathrm{NaCl}$ for 10 minutes, with 10 -minute intervals using the standard buffer. For the effect of diazoxide (Sigma-Aldrich), islets were perifused with Krebs-Ringer buffer containing $250 \mu \mathrm{M}$ diazoxide and $16.7 \mathrm{mM}$ glucose for 50 minutes. They were further perifused in the same buffer for 10 minutes, followed with the buffer containing $30 \mathrm{mM} \mathrm{kCl}$ plus $95 \mathrm{mM} \mathrm{NaCl}$ for 30 minutes, then with the prestimulation buffer for 15 minutes, in the continuous presence of diazoxide and glucose. All of the perifusate solution was equilibrated with $95 \% \mathrm{O}_{2}$ and $5 \% \mathrm{CO}_{2}$ and maintained at $37^{\circ} \mathrm{C}$. Fractions were collected every 1 minute, and the insulin secretion was measured.

Two-photon excitation imaging of exocytotic events in pancreatic islets. Exocytotic events of insulin granules inside living pancreatic islets were visualized with a solution containing a fluid-phase tracer, sulforhodamine B, using 2-photon excitation imaging, as described previously (21). Exocytotic events in response to glucose $(20 \mathrm{mM})$ were measured within an arbitrary area $\left(2,000 \mu \mathrm{m}^{2}\right)$ of islets. The dynamics of fusion pore opening were examined by measuring latency for the onset of staining with sulforhodamine B $(1.4 \mathrm{~nm})$ relative to that of staining with $10-\mathrm{kDa}$ fluorescein-dextran $(6 \mathrm{~nm})$. The cytosolic $\mathrm{Ca}^{2+}$ concentration was measured using Fura- 2 acetoxymethyl ester (Molecular Probes) as described previously (21).

TIRFM analysis of pancreatic $\beta$ cells. Analysis by TIRFM was performed using an inverted microscope (IX70; Olympus) with a high-aperture objective lens (Apo $\times 100$ OHR, NA 1.65; Olympus) as described previously (23). Briefly, isolated islets were dissociated into single cells by incubation in $\mathrm{Ca}^{2+}$-free Krebs-Ringer buffer containing $1 \mathrm{mM}$ EDTA and cultured on fibronectin-coated (Koken Co. Ltd.) high-refractive-index glass (Olympus). For immunocytochemical analysis, the cells were fixed and made permeable with $2 \%$ paraformaldehyde and $0.1 \%$ Triton X-100. For the observation of fusion events of GFP-labeled insulin granules, the cells were infected by adenovirus encoding GFP-tagged insulin (Adex1CA insulin-GFP).

$E M$ analysis. Animals were anesthetized with sodium pentobarbital and fixed by perfusion with $100 \mathrm{ml}$ of $2 \%$ paraformaldehyde and $2 \%$ glutaraldehyde in $0.1 \mathrm{M}$ cacodylate buffer, $\mathrm{pH} 7.4$, at $4^{\circ} \mathrm{C}$, followed by perfusion with $10 \mathrm{ml}$ of $0.86 \%$ saline solution. The pancreas was immersed in the same fixative for 3 hours at $4{ }^{\circ} \mathrm{C}$ and dissected into small blocks. The blocks containing pancreatic islets were further immersed into $10 \%$ sucrose in the cacodylate buffer for 1 hour at $4{ }^{\circ} \mathrm{C}$. They were then postfixed with $2 \%$ osmium tetroxide in the cacodylate buffer for 1.5 hours at $4^{\circ} \mathrm{C}$, dehydrated, infiltrated, and embedded in plastic resin. Ultrathin sections $(90 \mathrm{~nm}$ ) were cut on an Ultracut E ultramicrotome (Reichert-Jung), stained with uranyl acetate and lead citrate, and analyzed by a JEM 1010 electron microscope (JEOL).

For morphometric analysis, islets were isolated from mice by collagenase digestion and cultured overnight. They were then incubated in Krebs-Ringer buffer containing $2.8 \mathrm{mM}$ glucose at $37^{\circ} \mathrm{C}$ for 1 hour (nonstimulated islets), and some of them were further incubated in the buffer containing $25 \mathrm{mM}$ glucose for 30 minutes (stimulated islets). Both types of islet were fixed by immersion with $2 \%$ paraformaldehyde $/ 2 \%$ glutaraldehyde $/ 0.2 \%$ picric acid in $0.1 \mathrm{M}$ cacodylate buffer, $\mathrm{pH} 7.4$ for 1.5 hours at room temperature and embedded into $1 \%$ agarose. They were then postfixed, embedded in plastic resin, and sectioned as described above. Micrographs were randomly taken at $\times 5,000$ and $\times 8,000$ magnifications and captured with an image scanner (CC-500L, Epson) at 720 dots per inch. The entire cell circumference was included, and 10 individual $\beta$ cells derived from 2 mice were analyzed for each condition. The images at $\times 5,000$ magnification were used to measure the area of cytoplasm and the perimeter of the plasma membrane by ImageJ program (http://rsb.info.nih.gov/ij), whereas those at $\times 8,000$ magnification were used to count granules. The center of granules 
was determined and the number of granules located in concentric shells at increasing distance from the plasma membrane (100- or 200-nm thick as indicated) was counted.

Coimmunoprecipitation experiments. The isolated islets were placed in glucose-free Dulbecco's modified Eagle medium ( $2.8 \mathrm{mM}$ glucose) supplemented with $10 \%$ fetal calf serum and frozen at $-80^{\circ} \mathrm{C}$ until the cell lysis. Protein was extracted from 400-600 islets in $1 \mu \mathrm{l}$ per islet of lysis buffer containing $20 \mathrm{mM}$ Tris ( $\mathrm{pH} 7.5$ ), $150 \mathrm{mM} \mathrm{NaCl}, 2 \mathrm{mM} \mathrm{MgCl}_{2}, 1 \mathrm{mM}$ EGTA, $1.0 \%$ or $0.2 \%$ Triton-X 100 , and $1 \times$ protease inhibitor cocktail (Complete mini; Roche Diagnostics). After removal of insoluble materials by centrifugation at $15,000 \mathrm{rpm}$ for 30 minutes, the extracts were incubated with $30 \mu \mathrm{l}$ of a $50 \%$ slurry of protein G-Sepharose (Amersham Biosciences) for 3-4 hours at $4{ }^{\circ} \mathrm{C}$ under gentle rotation, and then centrifuged at 7,000 rpm for 3 minutes. The precleared extracts were then incubated with $5 \mu \mathrm{l}$ of anti-Munc18 serum (Synaptic Systems) or $\alpha \mathrm{Grp}-\mathrm{aC}$ overnight at $4^{\circ} \mathrm{C}$. The immune complexes were captured by an addition of $15 \mu \mathrm{l}$ of $50 \%$ protein G-Sepharose for 2 hours at $4^{\circ} \mathrm{C}$. Immunoprecipitates were washed 4 times with lysis buffer and finally dissolved in SDS-sample buffer. Immunoprecipitates and original precleared protein extracts were separated by SDS-polyacrylamide gel electrophoresis and were transferred onto an Immobilon-P membrane (Millipore). Protein interactions of syntaxin 1a with Munc18-1 or with granuphilin-a were analyzed by immunoblotting with anti-syntaxin $1 \mathrm{a}$ mouse monoclonal antibodies (HPC-1, 1:3,000 dilution; Sigma-Aldrich). The amount of Munc18-1 or granuphilin-a in each immunoprecipitate was evaluated by immunoblot analysis using anti-Munc18 mouse monoclonal antibodies (1:300 dilution; BD Biosciences - Pharmingen) and

1. Izumi, T., Gomi, H., Kasai, K., Mizutani, S., and Torii, S. 2003. The roles of Rab27 and its effectors in the regulated secretory pathways. Cell Struct. Funct. 28:465-474.

2. Tolmachova, T., et al. 2004. A general role for Rab27a in secretory cells. Mol. Biol. Cell. 15:332-344.

3. Söllner, T.H. 2003. Regulated exocytosis and SNARE function. Mol. Membr. Biol. 20:209-220.

4. Blott, E.J., and Griffiths, G.M. 2002. Secretory lysosomes. Nat. Rev. Mol. Cell Biol. 3:122-131.

5. Nagashima, K., et al. 2002. Melanophilin directly links Rab27a and myosin Va through its distinct coiled-coil regions. FEBS Lett. 517:233-238.

6. Kuroda, T.S., Fukuda, M., Ariga, H., and Mikoshiba, K. 2002. The Slp homology domain of synaptotagmin-like proteins 1-4 and Slac2 functions as a novel Rab27A binding domain. J. Biol. Chem. 277:9212-9218.

7. Ménasché, G., et al. 2000. Mutations in RAB27A cause Griscelli syndrome associated with haemophagocytic syndrome. Nat. Genet. 25:173-176.

8. Wilson, S.M., et al. 2000. A mutation in Rab27A causes the vesicle transport defects observed in ashen mice. Proc. Natl. Acad. Sci. U. S. A. 97:7933-7938.

9. Yi, Z., et al. 2002. The Rab27a/granuphilin complex regulates the exocytosis of insulin-containing dense-core granules. Mol. Cell. Biol. 22:1858-1867.

10. Wang, J., Takeuchi, T., Yokota, H., and Izumi, T. 1999. Novel rabphilin-3-like protein associates with insulin-containing granules in pancreatic beta cells. J. Biol. Chem. 274:28542-28548.

11. Torii, S., et al. 2002. Granuphilin modulates the exocytosis of secretory granules through the interaction with syntaxin 1a. Mol. Cell. Biol. 22:5518-5526.

12. Torii, S., Takeuchi, T., Nagamatsu, S., and Izumi, T. 2004. Rab27 effector granuphilin promotes $\alpha G r p-N(1: 2,000$ dilution). Chemiluminescent signals on the $x$-ray film were captured with a scanner and quantified using Gel Plotting Macros of NIH Image 1.62 program (http://rsb.info.nih.gov/nih-image).

Statistical analysis. Most analyses comparing the average between 2 groups were done by Student's $t$ test. Perifusion data were analyzed by repeated-measures ANOVA. Immunoblot signals were analyzed by a Wilcoxon signed-ranks test.

\section{Acknowledgments}

We thank T. Takeuchi, S. Torii, H. Yokota-Hashimoto, H. Takemura, T. Ishizaka, N. Satoh (Gunma University), and C. Nishiwaki (Kyorin University) for generous support. This work was supported by grants-in-aid for scientific research and the 21st Century Center of Excellence Program from the Ministry of Education, Culture, Sports, Science, and Technology of Japan. It was also supported by grants from the Takeda Science Foundation, The Naito Foundation, the Daiwa Securities Health Foundation, and by a Japan Insulin Study Group Award (to T. Izumi).

Received for publication August 6, 2004, and accepted in revised form November 16, 2004.

Address correspondence to: Tetsuro Izumi, Department of Molecular Medicine, Institute for Molecular and Cellular Regulation, Gunma University, 3-39-15 Showa-machi, Maebashi, Gunma 371-8512, Japan. Phone: 81-27-220-8856; Fax: 81-27-220-8860; E-mail: tizumi@showa.gunma-u.ac.jp. the plasma membrane targeting of insulin granules via interaction with syntaxin 1a. J. Biol. Chem. 279:22532-22538.

13. Haddad, E.K., Wu, X., Hammer, J.A., III, and Henkart, P.A. 2001. Defective granule exocytosis in Rab27a-deficient lymphocytes from ashen mice. J. Cell Biol. 152:835-841.

14. Stinchcombe, J.C., et al. 2001. Rab27a is required for regulated secretion in cytotoxic T lymphocytes. J. Cell Biol. 152:825-833.

15. Barral, D.C., et al. 2002. Functional redundancy of Rab27 proteins and the pathogenesis of Griscelli syndrome. J. Clin. Invest. 110:247-257. doi:10.1172/ JCI200215058.

16. Zhao, S., Torii, S., Yokota-Hashimoto, H., Takeuchi, T., and Izumi, T. 2002. Involvement of Rab27b in the regulated secretion of pituitary hormones. Endocrinology. 143:1817-1824.

17. Wu, X.S., et al. 2002. Identification of an organelle receptor for myosin-Va. Nat. Cell Biol. 4:271-278.

18. Hirayama, I., et al. 1999. Genetic analysis of obese diabetes in the TSOD mouse. Diabetes. 48:1183-1191.

19. Aizawa, T., Komatsu, M., Asanuma, N., Sato, Y., and Sharp, G.W.G. 1998. Glucose action 'beyond ionic events' in the pancreatic $\beta$ cells. Trends Pharmacol. Sci. 19:496-499.

20. Henquin, J.-C. 2000. Triggering and amplifying pathways of regulation of insulin secretion by glucose. Diabetes. 49:1751-1760.

21. Takahashi, N., Kishimoto, T., Nemoto, T., Kadowaki, T., and Kasai, H. 2002. Fusion pore dynamics and insulin granule exocytosis in the pancreatic islet. Science. 297:1349-1352.

22. Steyer, J.A., and Almers, W. 2001. A real-time view of life within $100 \mathrm{~nm}$ of the plasma membrane. Nat. Rev. Mol. Cell Biol. 2:268-276.
23. Ohara-Imaizumi, M., et al. 2004. TIRF imaging of docking and fusion of single insulin granule motion in primary rat pancreatic $\beta$-cells: different behaviour of granule motion between normal and Goto-Kakizaki diabetic rat $\beta$-cells. Biochem. J. 381:13-18.

24. Olofsson, C.S., et al. 2002. Fast insulin secretion reflects exocytosis of docked granules in mouse pancreatic B-cells. Pflügers Arch. 444:43-51.

25. Hata, Y., Slaughter, C.A., and Südhof, T.C. 1993. Synaptic vesicle fusion complex contains unc-18 homologue bound to syntaxin. Nature. 366:347-351.

26. Steyer, J.A., Horstmann, H., and Almers, W. 1997. Transport, docking and exocytosis of single secretory granules in live chromaffin cells. Nature. 388:474-478.

27. Plattner, H., Artalejo, A.R., and Neher, E. 1997. Ultrastructural organization of bovine chromaffin cell cortex: analysis by cryofixation and morphometry of aspects pertinent to exocytosis. J. Cell Biol. 139:1709-1717.

28. Olsen, H.L., et al. 2003. Phosphatidylinositol 4-kinase serves as a metabolic sensor and regulates priming of secretory granules in pancreatic $\beta$ cells. Proc. Natl. Acad. Sci. U. S. A. 100:5187-5192.

29. Ohara-Imaizumi, M., et al. 2004. Site of docking and fusion of insulin secretory granules in live MIN6 $\beta$ cells analyzed by TAT-conjugated anti-syntaxin 1 antibody and total internal reflection fluorescence microscopy. J. Biol. Chem. 279:8403-8408.

30. Klein, C., et al. 1994. Partial albinism with immunodeficiency (Griscelli syndrome). J. Pediatr. 125:886-895.

31. Izumi, T., et al. 2003. Dominant negative pathogenesis by mutant proinsulin in the Akita diabetic mouse. Diabetes. 52:409-416. 